\title{
Light Transduction in Invertebrate Hyperpolarizing Photoreceptors: Possible Involvement of a $\mathbf{G}_{0}$-Regulated Guanylate Cyclase
}

\author{
Maria del Pilar Gomez and Enrico Nasi \\ Department of Physiology, Boston University School of Medicine, Boston, Massachusetts 02118, and Marine Biological \\ Laboratory, Woods Hole, Massachusetts 02543
}

\begin{abstract}
The hyperpolarizing receptor potential of scallop ciliary photoreceptors is attributable to light-induced opening of $\mathrm{K}^{+}$-selective channels. Having previously demonstrated the activation of this $\mathrm{K}^{+}$current by cGMP, we examined upstream events in the transduction cascade. GTP- $\gamma$-S produced persistent excitation after a flash, accompanied by decreased sensitivity and acceleration of the photocurrent, whereas GDP- $\beta$-S only inhibited responsiveness, consistent with the involvement of a G-protein. Because $G_{o}$ (but not $G_{t}$ nor $G_{q}$ ) recently has been detected in the ciliary retinal layer of a related species, we tested the effects of activators of $\mathrm{G}_{\mathrm{o}}$; mastoparan peptides induced an outward current suppressible by blockers of the light-sensitive conductance such as L-cis-diltiazem. In addition, intracellular dialysis with the A-protomer of pertussis toxin (PTX) depressed the photocurrent. The mechanisms that couple G-protein stimulation to changes in cGMP were investigated. Intracellular IBMX enhanced the pho-
\end{abstract}

toresponse with little effect on the baseline current, a result that argues against regulation by light of phosphodiesterase activity. LY83583, an inhibitor of guanylate cyclase (GC), exerted a reversible, dose-dependent suppression of the photocurrent. By contrast, ODQ, an antagonist of NO-sensitive GC, and YC-1, an activator of NO-sensitive GC, failed to alter the light response or the holding current; furthermore, the NO synthase inhibitor $\mathrm{N}$-methyl- L-arginine was inert, indicating that the NO signaling pathway is not implicated. Taken together, these results suggest a novel type of phototransduction cascade in which stimulation of a PTX-sensitive $G_{0}$ may activate a membrane $G C$ to induce an increase in cGMP and the consequent opening of lightdependent channels.

Key words: invertebrate photoreceptors; light-dependent channels; phototransduction; cGMP; guanylate cyclase; PDE; PTX; G-protein
The retinas of the scallop and other marine mollusks contain a layer of ciliary photoreceptors that, unlike those of most invertebrates, hyperpolarize in response to photostimulation (McReynolds, 1976), owing to a light-induced increase in a potassiumselective conductance (Gorman and McReynolds, 1978; Gomez and Nasi, 1994a). We previously showed that cGMP analogs activate a $\mathrm{K}^{+}$current with similar conduction and pharmacology as the photocurrent. Furthermore, cGMP interacts occlusively with light stimulation (Gomez and Nasi, 1995), suggesting that it functions as a second messenger in phototransduction. Such a proposition raises the question of which mechanisms link photopigment stimulation to the changes in cytosolic cGMP concentration that are required to regulate the light-sensitive conductance.

In rhabdomeric (depolarizing) photoreceptors rhodopsin activates a G-protein of the $\mathrm{G}_{\mathrm{q}}$ subtype (Lee et al., 1994; Scott et al., 1995; Suzuki et al., 1995) and stimulates a phospholipase C (PLC) (Devary et al., 1987; Baer and Saibil, 1988) with the consequent hydrolysis of $\mathrm{PIP}_{2}, \mathrm{IP}_{3}$ production (Szuts et al., 1986; Brown et al., 1987), and $\mathrm{Ca}^{2+}$ release (Brown and Blinks, 1974; Brown and Rubin, 1984). In scallop hyperpolarizing photoreceptors, however, neither $\mathrm{IP}_{3}$ nor $\mathrm{Ca}^{2+}$ plays any important role in transduction (Gomez and Nasi, 1995), making $\mathrm{G}_{\mathrm{q}}$ a poor candidate. The rhodopsin-stimulated G-protein of vertebrate photoreceptors is transducin $\left(G_{t}\right) ; G_{t}$ activates a phosphodiesterase (PDE), leading to hydrolysis of cGMP, the substance that opens the light-sensitive channels (for review, see Yau and Baylor, 1989). Considering the structural and functional similarities between hyperpolarizing invertebrate photoreceptors and rods and cones (Miller, 1958; Gomez and Nasi, 1997a), one may suggest a role for transducin; in such a case the cascade would have to diverge downstream, because light is expected to increase cGMP. In a recent study Kojima et al.

\footnotetext{
Received Jan. 31, 2000; revised April 28, 2000; accepted May 3, 2000.

This work was supported by National Institutes of Health Grant RO1-EY07559.

Correspondence should be addressed to Dr. Maria del Pilar Gomez, Department of Physiology, Boston University School of Medicine, 715 Albany Street, Boston, MA 02118. E-mail: mpgomez@bu.edu.

Copyright (C) 2000 Society for Neuroscience $0270-6474 / 00 / 205254-10 \$ 15.00 / 0$
}

(1997) examined the G-proteins present in the retina of a related species and demonstrated that the only isoform that localizes to the distal layer, where ciliary receptors are found, belongs to the $G_{\alpha o}$ subtype. However, no functional evidence was provided to confirm the involvement of a G-protein in phototransduction nor to suggest its identity.

A further question concerns the enzymatic regulation of [cGMP]; if the photoresponse requires an increase in cGMP, two prime light-triggered mechanisms may be a decrease in the activity of a PDE or stimulation of a guanylate cyclase (GC). The former case is a mirror image of the mechanism that operates in rods and cones and resembles phototransduction in the parietal eye of the lizard, as recently described by Xiong et al. (1998), whereas the latter has no precedent as a mechanism to generate the receptor potential in retinal cells. In the present report we used whole-cell patch-clamp recordings of isolated ciliary photoreceptors to obtain evidence that a PTX-sensitive G-protein, most likely of the $G_{o}$ subclass, mediates phototransduction in Pecten irradians (and probably in other invertebrate ciliary photoreceptors). Our results do not provide support for the involvement of a light-regulated PDE as a downstream effector; rather, the possibility of a key role of a GC suggests itself. The departure of such a scheme from established mechanisms that generate the light response in other visual cells is indicative of a novel type of phototransduction cascade.

\section{MATERIALS AND METHODS}

Specimens of Pecten irradians were obtained from the Marine Resources Center at the Marine Biological Laboratory (Woods Hole, MA) and used immediately. Isolated retinas were dispersed enzymatically and mechanically as described (Gomez and Nasi, 1994a), and the resulting cell suspension was plated in a recording flow chamber pretreated with Concanavalin A (Sigma, St. Louis, MO) to promote cell adhesion (Nasi, 1991). During the experiments the chamber was superfused continuously with artificial seawater (ASW) containing (in mM) $480 \mathrm{NaCl}, 10 \mathrm{KCl}, 49 \mathrm{MgCl}_{2}, 10$ $\mathrm{CaCl}_{2}, 10$ HEPES, and 5 glucose, $\mathrm{pH} 7.8$ (adjusted with $\mathrm{NaOH}$ ). Extracellular chemical stimulation was accomplished by a puffer pipette (tip outer diameter of $3-4 \mu \mathrm{m}$ ) positioned $\sim 30-50 \mu \mathrm{m}$ from the target cell. Application of pressurized nitrogen (1-3 psi) to the pipette via a solenoidoperated valve permitted local solution exchange in $<400 \mathrm{msec}$ (Gomez 
and Nasi, 1996). Patch electrodes were fabricated with thin-wall borosilicate capillary tubing (7052, Garner Glass, Claremont, CA), fire-polished, and filled with an "intracellular" solution containing (in mM) $100 \mathrm{KCl}, 200$ K-aspartate or K-glutamate, $5 \mathrm{Na}_{2} \mathrm{ATP}, 12 \mathrm{NaCl}, 6 \mathrm{MgCl}_{2}, 10 \mathrm{HEPES}, 1$ EGTA, 0.2 GTP and 300 sucrose, pH 7.3. Electrode resistance, measured in ASW, ranged between 2 and $6 \mathrm{M} \Omega$. Series resistance errors were corrected via a positive feedback circuit in the amplifier (maximal residual error typically $<2 \mathrm{mV}$ ). For internal dialysis, test substances were added to the electrode filling solution from stock solutions. In all experiments the holding potential was $-30 \mathrm{mV}$.

GTP- $\gamma$-S (guanosine $5^{\prime}-O$-[3-thiotriphosphate]), GDP- $\beta$-S (guanosine 5 - $O$-[2-thiodiphosphate]), 8-bromo-cyclic guanosine monophosphate (8Br-cGMP), EHNA (erythro-9-[2-hydroxy-3-nonyl]adenine $\mathrm{HCl}$ ), trequinsine, and the A-protomer of pertussis toxin (PTX) were purchased from Sigma. PTX (holotoxin) and mastoparan were obtained from Calbiochem (San Diego, CA), whereas the related peptides MAS-7 and MAS 17 were obtained from Peninsula Laboratories (San Carlos, CA). The calmodulin antagonists W-7 hydrochloride [ $N$-(6-aminohexyl)-5-chloro-1-naphthalenesulfonamide $(\mathrm{HCl})]$ and chlorpromazine were purchased from Research Biochemicals (Natick, MA).

LY83583 (6-anilino-5,8-quinolinedione) was obtained from Calbiochem, whereas calmidozolium chloride and YC-1 (3-[5'-hydroxymethyl-2'furyl]1-benzyl indazole) were from Research Biochemicals. ODQ (1H$[1,2,4]$ oxadiazolol-[4,3-a]quinoxalin-1-one) and the phosphodiesterase inhibitors IBMX (3-isobutyl-1-methylxanthine), 8-methoxymethyl-IBMX, dipyridamole, zaprinast [1,4-dihydro-5-(2-propoxyphenyl)- $7 \mathrm{H}$-1,2,3-triazolo4,5-dipyrymidin-7-one], and milrinone (1,6-dihydro-2-methyl-6-oxo-3,4bipyridine-5-carbonitrile) were obtained from Sigma. These water-insoluble substances were dissolved in either EtOH or DMSO, and the stock solutions were aliquoted and stored at $-80^{\circ} \mathrm{C}$. The final concentration of DMSO or EtOH present either in the internal solution or in ASW was $<0.5 \%$. Control experiments demonstrated that solvent concentrations up to $5 \%$ were inert on the membrane current and on the light response of ciliary photoreceptors.

Flashes and steps of broadband light $(515-650 \mathrm{~nm})$ generated by a standard optical stimulator (Gomez and Nasi, 1994a) were calibrated in vivo, as previously described (Gomez and Nasi, 1994a,b). Light intensity is expressed either in terms of equivalent photon flux at $500 \mathrm{~nm}$ or, whenever light attenuation was varied within a given protocol, as $\log _{10}\left(I / I_{\mathrm{o}}\right)$, where $I_{\mathrm{o}}$ is the intensity of the unattenuated light. Calibrated neutral-density filters (Melles Griot, Irvine, CA) provided controlled attenuation. During experimental manipulations the cells were illuminated with near-IR light with a long-pass filter $(\lambda>780 \mathrm{~nm}$; Andover, Salem, NH) and viewed with the aid of a Newvicon TV camera (model WV-1550, Panasonic, Secaucus, NJ). The infrared illuminator was turned off for several minutes before light responses were tested. All recordings were made at room temperature $\left(20-22^{\circ} \mathrm{C}\right)$.

\section{RESULTS}

\section{Involvement of a G-protein}

Nonhydrolyzable analogs of GTP, such as GTP- $\gamma$-S, have been used extensively to assess the participation of G-proteins in cell signaling (Breitwieser and Szabo, 1988; Andrade, 1994). At low doses GTP- $\gamma-\mathrm{S}$ is not expected to activate the G-protein, but on stimulation of the receptor it should induce a prolongation of the response by interfering with a key shut-off step, namely the GTPase action of $\mathrm{G}_{\alpha}$. Figure $1 \mathrm{~A}$, left, shows the membrane current from a ciliary photoreceptor internally perfused with $100 \mu \mathrm{M}$ GTP- $\gamma-\mathrm{S}$ and stimulated repetitively with 5 sec light steps at intervals of 40 sec. A substantial fraction of the photocurrent remained active after the termination of the first light stimulus; subsequent lights evoked progressively diminished responses and smaller further shifts in baseline $(n=16)$. By contrast, in control cells dialyzed with the normal intracellular solution the photocurrents shut off completely after each light (Fig. $1 A$, right), and their peak amplitude remained unaltered with successive repetitions of the stimulus $(n>20)$. The progressive reduction in responsiveness in the presence of GTP- $\gamma$-S required photostimulation, as illustrated in Figure $1 B$, top; a cell internally perfused with $100 \mu \mathrm{M}$ GTP- $\gamma$-S for $15 \mathrm{~min}$ in the dark responded to the first flash with a photocurrent of normal amplitude. Subsequent light responses, however, were profoundly depressed $(n=4)$. For comparison, the bottom trace illustrates the outcome of a similar regime applied to a control cell.

When photoreceptors are stimulated with persistent background illumination, the response to a test flash is desensitized; in addition, it acquires a more rapid time course (Fuortes and Hodgkin, 1964; Baylor and Hodgkin, 1974). If the depression of the light response in GTP- $\gamma$-S-treated photoreceptors is a consequence of sustained activation of the transduction cascade, one may expect a similar acceleration of the photocurrent. Figure $2 A$, left, shows superim-
A
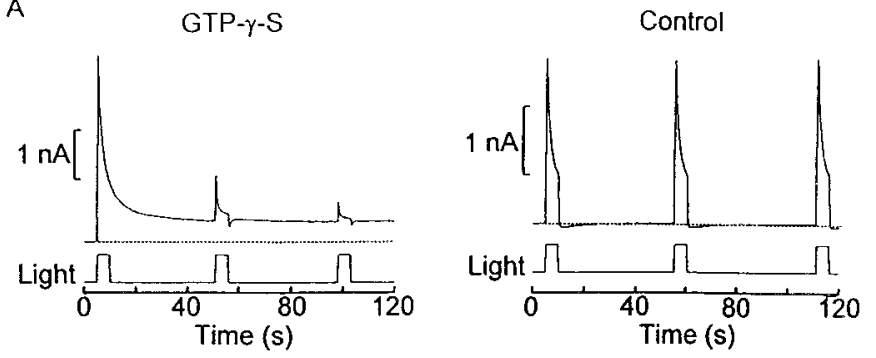

B
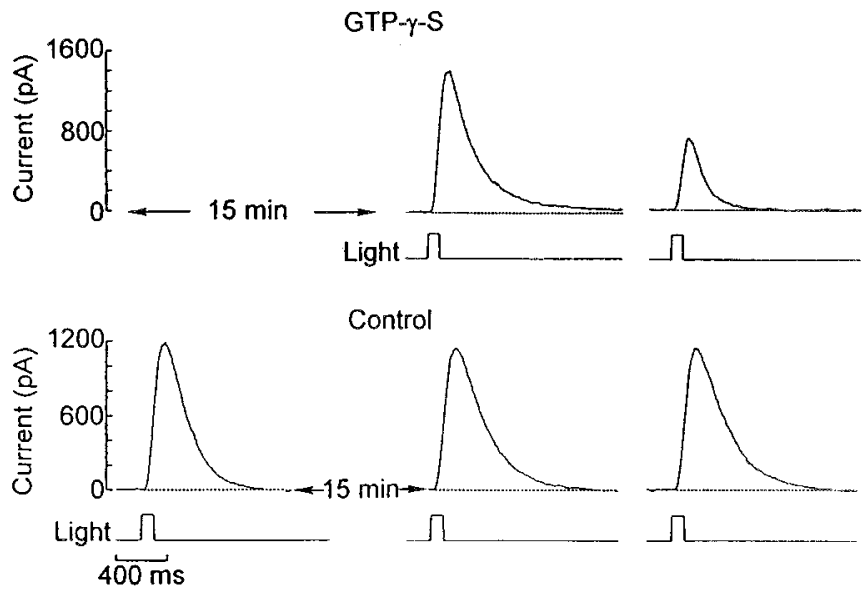

Figure 1. Effects of GTP- $\gamma$-S on the photocurrent. A, Left, A photoreceptor was whole-cell-clamped with an electrode containing $100 \mu \mathrm{M}$ GTP- $\gamma-\mathrm{S}$. Light-steps lasting for $5 \mathrm{sec}$ were applied every $40 \mathrm{sec}\left(28 \times 10^{14}\right.$ photons $\times$ $\left.\mathrm{sec}^{-1} \times \mathrm{cm}^{-2}\right)$. At the termination of the first light stimulus, a substantial fraction of the photocurrent remained active. A, Right, A control cell dialyzed with the standard intracellular solution was subjected to a similar protocol $\left(17.6 \times 10^{14}\right.$ photons $\left.\times \mathrm{sec}^{-1} \times \mathrm{cm}^{-2}\right)$ and displayed no sustained activation of the photoresponses. $B$, The decline in light responsiveness with GTP- $\gamma$-S is a consequence of photostimulation. Top, A photoreceptor internally perfused with $100 \mu \mathrm{M} \mathrm{GTP}-\gamma$-S was kept in the dark for 15 min before light stimulation. The first photocurrent in response to a flash of $7 \times 10^{14}$ photons $\times \mathrm{sec}^{-1} \times \mathrm{cm}^{-2}$ displayed normal amplitude, whereas a subsequent response to the same light stimulus applied 2 min later was severely depressed. Bottom, A cell dialyzed with normal internal solution was stimulated immediately after attaining the whole-cell configuration and then kept in the dark for 15 min before stimulation was resumed. The responses show no deterioration. Light intensity, $2.3 \times 10^{14}$ photons $\times$ $\mathrm{sec}^{-1} \times \mathrm{cm}^{-2}$.

posed photocurrents elicited by $100 \mathrm{msec}$ flashes delivered every 2 min during intracellular dialysis with $100 \mu \mathrm{M} \mathrm{GTP}-\gamma-\mathrm{S}$. In the panel on the right the traces were normalized with respect to the peak amplitude, revealing that the kinetics of the response became progressively faster. Similar results were obtained in 12 cells. Figure $2 B$ shows superimposed light responses from a control cell, demonstrating the lack of any acceleration of their time course $(n>50)$.

Whereas the effectiveness of GTP- $\gamma$-S at low doses requires activation of the receptor, one would anticipate that, by the law of mass action, higher concentrations should be capable of directly stimulating the G-protein (Breitwieser and Szabo, 1988). This prediction is borne out by the data in Figure $3 A$, which shows membrane currents recorded from different photoreceptors in the dark immediately after intracellular perfusion was initiated with the indicated concentrations of GTP- $\gamma$-S. When the intracellular solution contained $>100 \mu \mathrm{M}$ GTP- $\gamma$-S, a conspicuous outward current gradually developed. Figure $3 B$ shows the mean peak amplitude of outward membrane currents recorded in the dark, pooled from cells treated with the different concentrations of GTP- $\gamma$-S (total $n=14$ ).

A complementary strategy to ascertain the involvement of a G-protein entails the use of GDP- $\beta$-S. This hydrolysis-resistant 


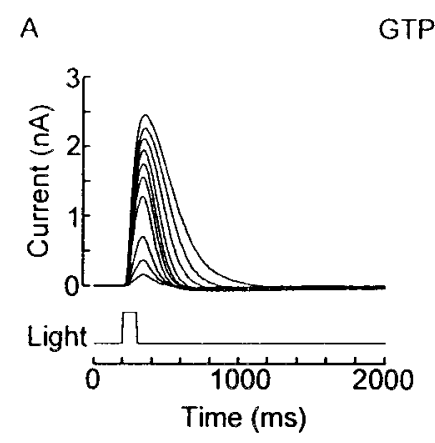

GTP- $\gamma-S$

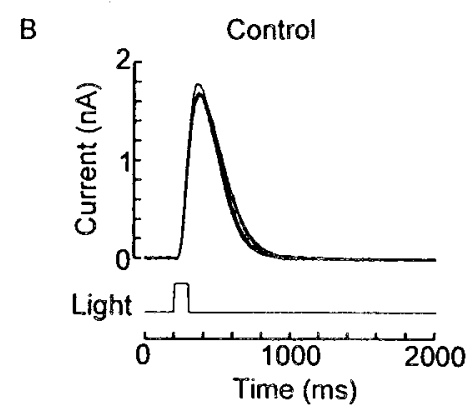

Figure 2. GTP- $\gamma$ - $S$-induced desensitization is accompanied by photocurrent acceleration. $A$, Left, Repetitive flashes $\left(100 \mathrm{msec} ; 4.4 \times 10^{14}\right.$ photons $\times \mathrm{sec}^{-1} \times \mathrm{cm}^{-2}$ ) were applied every $2 \mathrm{~min}$ to a photoreceptor dialyzed with $100 \mu \mathrm{M}$ GTP- $\gamma-\mathrm{S}$; the response amplitude gradually decreased. $A$, Right, Normalization of the same photocurrent traces reveals progressively faster kinetics. $B$, Superimposed light responses $\left(3.3 \times 10^{14}\right.$ photons $\times \mathrm{sec}^{-1} \times \mathrm{cm}^{-2}$ ) in a control cell, demonstrating the lack of any significant change in either amplitude or time course.
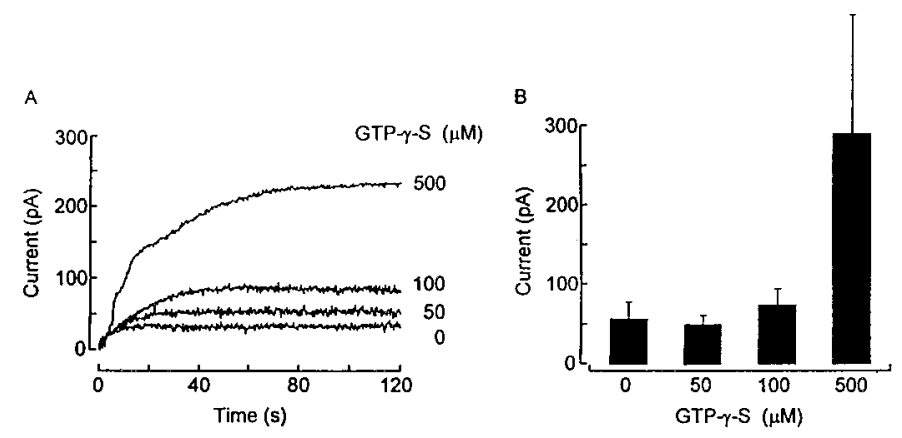

Figure 3. Direct stimulatory effects of GTP- $\gamma$-S at higher concentrations. $A$, Whole-cell membrane currents measured in the dark in four different cells immediately after the initiation of intracellular perfusion with the concentrations of GTP- $\gamma$-S indicated on the right. When [GTP- $\gamma$-S] in the pipette was above $100 \mu \mathrm{M}$, a conspicuous outward current gradually developed. $B$, Mean peak amplitude of outward membrane currents recorded in the dark, pooled from cells treated with different concentrations of GTP- $\gamma$-S.

GDP analog acts as a competitive inhibitor of G-proteins by binding to the $\alpha$-subunit and preventing agonist-induced activation (Eckstein et al., 1979). Figure $4 A$ shows the responses evoked by $100 \mathrm{msec}$ flashes of constant intensity applied every minute to a cell dialyzed with $200 \mu \mathrm{M}$ GDP- $\beta$-S. A marked decrease in the amplitude of the photocurrent took place over a period of $15 \mathrm{~min}(n=$ 4). However, unlike with GTP- $\gamma$-S, the progressive decline in light responsiveness occurred irrespective of light stimulation, as illustrated in Figure $4 B$; a step of light was interposed between two brief test flashes delivered 2 min apart (an interval far shorter than the time constant of the decay of the GDP- $\beta$-S-induced loss of responsiveness; see Fig. $4 A$ ). The response to the second test flash barely displayed some attenuation (top; $n=6$ ); by contrast, in GTP- $\gamma$-S-treated cells light responsiveness was reduced dramatically by the intervening conditioning light (bottom; $n=8$ ).
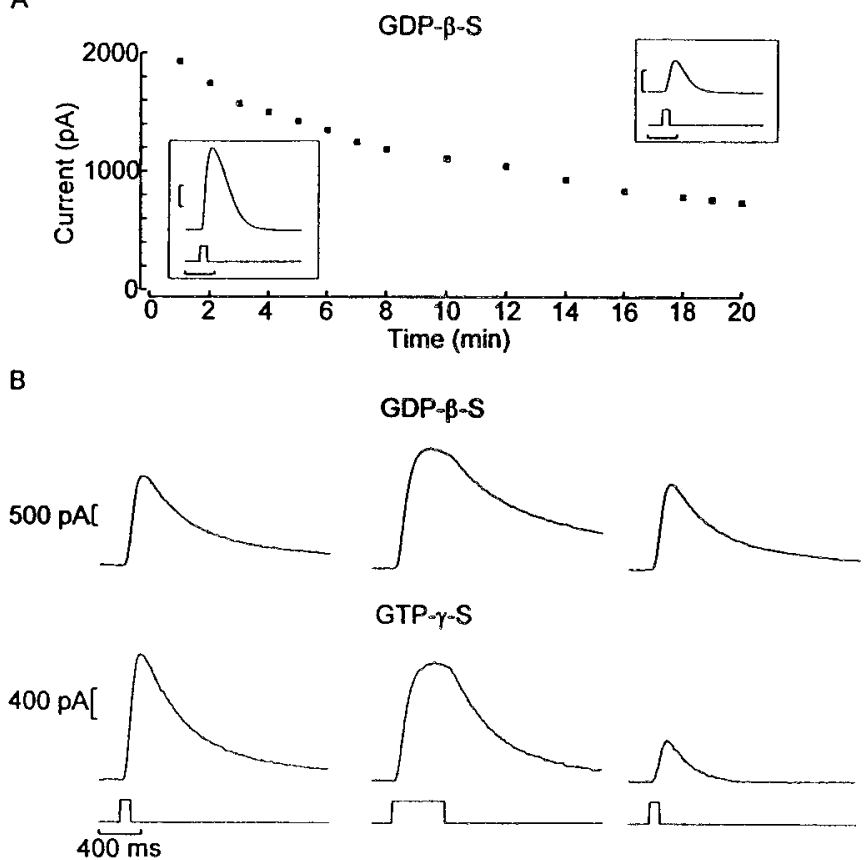

Figure 4. GDP- $\beta$-S reduces light responsiveness. $A$, Peak amplitude of responses elicited by $100 \mathrm{msec}$ flashes, plotted as a function of time. The photoreceptor was voltage-clamped with an electrode containing $200 \mu \mathrm{M}$ GDP- $\beta$-S. Insets, First and last record of the series. Calibration: $400 \mathrm{msec}$, 400 pA. $B$, Light stimulation does not potentiate the effect of GDP- $\beta$-S. The stimulus protocol consisted of a control flash $(100 \mathrm{msec})$ followed by a conditioning $500 \mathrm{msec}$ light of the same intensity and a second test flash (identical to the control); this regime was repeated at 2 min intervals. Top, Responses from a cell dialyzed with GDP- $\beta$-S, showing only minor changes in the photocurrent evoked by the test flashes. Bottom, When the same protocol was applied to a photoreceptor internally perfused with GTP- $\gamma-\mathrm{S}$, the conditioning light dramatically depressed the response to the test flash. Light intensity, $7 \times 10^{14}$ photons $\times \mathrm{sec}^{-1} \times \mathrm{cm}^{-2}$.

To corroborate further that the desensitizing effect of poorly hydrolyzable guanine nucleotide analogs is not attributable to inhibition of downstream elements in the cascade, we determined that activation of the conductance by 8 -Br-cGMP $(20 \mu \mathrm{M})$ was not hindered by concomitant dialysis with $100 \mu \mathrm{M}$ GTP- $\gamma-\mathrm{S}(n=5$; data not shown).

In summary, we demonstrated the following: (1) sustained photoexcitation in the presence of low doses of GTP- $\gamma-\mathrm{S}$, accompanied by response desensitization and acceleration of its kinetics; (2) direct channel activation at high doses of GTP- $\gamma-\mathrm{S}$; and (3) inhibition of the photoresponse by GDP- $\beta$-S. Taken together, these results strongly suggest that, like in other classes of visual cells, a G-protein mediates light transduction in the hyperpolarizing ciliary photoreceptors of the scallop.

\section{Identity of the G-protein}

Considering that a $\mathrm{G}_{\alpha \mathrm{o}}$ has been detected in the ciliary retinal layer of another species of scallop (Kojima et al., 1997), we sought physiological support for the proposition that this subclass of $\mathrm{G}$-protein is involved in the phototransduction process. Among the substances that have been described as activators of G-proteins, mastoparan, a small peptide component of wasp venom, has been shown to display a significant selectivity for $G_{i}$ and $G_{o}$ isoforms and to operate by a mechanism that mimics stimulation by activated receptors (Higashijima et al., 1988). Figure $5 A$ shows membrane current traces recorded in the dark from different photoreceptors immediately after the whole-cell configuration was attained. The patch electrodes contained 0,20 , or $50 \mu \mathrm{M}$ mastoparan, and the holding potential was set at $-30 \mathrm{mV}$. With the control internal solution no significant change in holding current was observed. With $20 \mu \mathrm{M}$ mastoparan an outward current developed after a latency of $\sim 10 \mathrm{sec}$, attaining an amplitude of $226 \mathrm{pA}$ (mean $222 \pm$ 

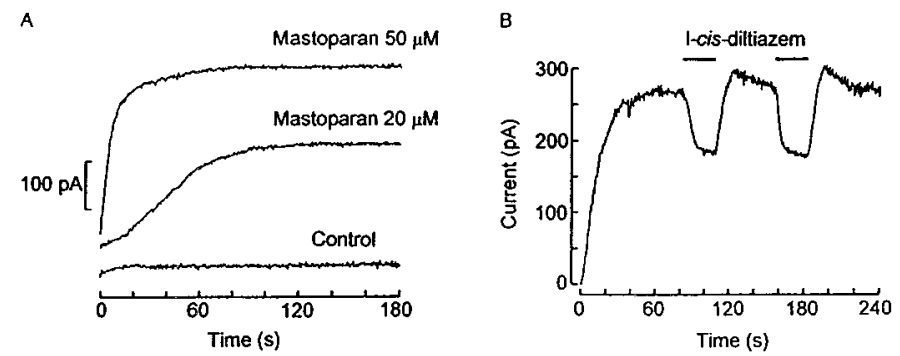

Figure 5. Mastoparan-induced outward current. $A$, Whole-cell membrane current measured in the dark immediately after internal perfusion was initiated. The patch pipette contained either control internal solution or mastoparan at a concentration of 20 or $50 \mu \mathrm{M}$, respectively. A distinct outward current developed in the photoreceptors treated with mastoparan; the amplitude and speed of the response were related directly to the peptide concentration. $B$, Current trace recorded in the dark from a cell internally dialyzed with $20 \mu \mathrm{M}$ mastoparan. When the outward current attained a steady level, $1 \mathrm{~mm}$ L-cis-diltiazem was applied repeatedly by a puffer pipette (indicated by the bars), producing a reversible decrease in the amplitude of the response.

$140 \mathrm{pA} ; n=18)$. With $50 \mu \mathrm{M}$ a much faster and larger response was obtained (mean $361 \pm 177 \mathrm{pA} ; n=4)$. These effects bear a striking resemblance to the direct stimulation of the light-sensitive conductance by intracellular application of cGMP analogs (Gomez and Nasi, 1995), although the average size of the mastoparan-induced current tended to be smaller than that evoked by application of 8-Br-cGMP. Extending the range of concentrations of mastoparan proved to be problematic because at high doses this substance also has been reported to permeabilize the plasma membrane (Tanimura et al., 1991) by inducing the formation of nonselective cationic membrane pores (Suh et al., 1996). In fact, a few attempts that used larger amounts of the peptide in the pipette solution resulted in a runaway increase in leakage. Other peptides related to mastoparan also were tested. MAS 17, a relatively inactive analog obtained by introducing a positively charged lysine on the hydrophobic stretch of the molecule, proved significantly less potent than mastoparan $(20 \mu \mathrm{M} ; n=5)$. By contrast, MAS 7, which is produced by a lysine $\rightarrow$ alanine substitution at position 12 , resulting in an enhanced ability to promote GDP/GTP exchange in G-proteins (Higashijima et al., 1988), also evoked a conspicuous outward current in the dark when dialyzed at a concentration of $20 \mu \mathrm{M}(n=$ 3 ); in our hands, however, its effectiveness was not greater than that of mastoparan.

To ascertain whether the mastoparan-evoked current is related to the activation of the phototransduction cascade, we examined the effects of blockers of light-dependent channels on the current induced by this peptide. In Figure $5 B$ a photoreceptor cell was held at $-30 \mathrm{mV}$ and dialyzed intracellularly with $20 \mu \mathrm{M}$ mastoparan, which induced an outward current of $284 \mathrm{pA}$. When a stable level was attained, $1 \mathrm{~mm}$ L-cis-diltiazem was applied by puffer pipette, rapidly producing a substantial, reversible decrease in the outward current. Similar results were obtained in six cells. No effects of the blocker were seen in the absence of mastoparan (data not shown). The degree of blockage of the mastoparan-induced current by L-cis-diltiazem was quantitatively comparable to that previously reported for the light-evoked current and for the current elicited by 8-Br-cGMP (Gomez and Nasi, 1997a). Similarly, puffer application of $100 \mu \mathrm{M} 4$-AP, which previously was shown to potently block the photocurrent in these cells (Gomez and Nasi, 1994b), antagonized the mastoparan-elicited outward current ( $n=2$; data not shown). Further clues were provided by evidence of occlusive interactions between mastoparan and light stimulation; after dialysis with the peptide the peak amplitude of the current evoked by a flash of saturating intensity was smaller than in control photoreceptors (966 $\pm 732 \mathrm{pA}$ vs $2460 \pm 907 \mathrm{pA} ; n=9$ in each condition). Moreover, in treated cells a significant negative correlation existed between the size of the current elicited by mastoparan and that of the residual photocurrent $(r=-0.46 ; p<0.05)$.

Mastoparan is also known as a calmodulin (CaM) inhibitor
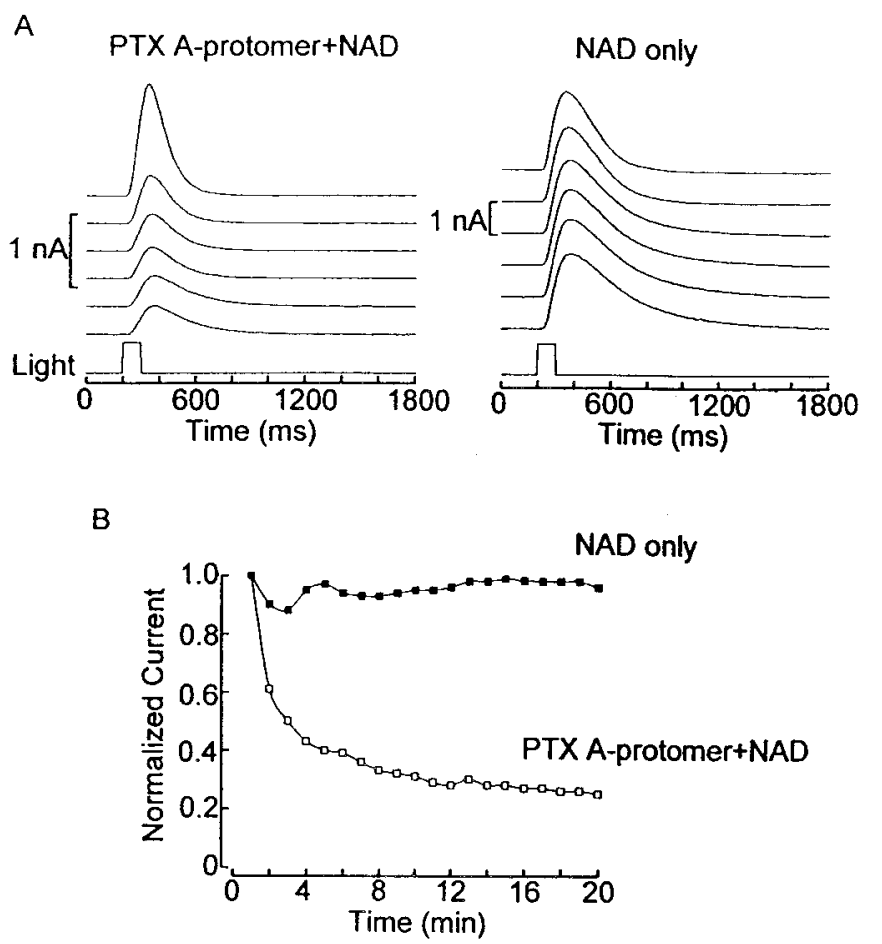

Figure 6. Pertussis toxin sensitivity of the light-dependent current. A, Left, Shown are responses to repetitive $100 \mathrm{msec}$ flashes from a cell codialyzed with the PTX A-protomer $(3 \mu \mathrm{g} / \mathrm{ml})$ and NAD $(500 \mu \mathrm{M})$. A progressive reduction of photocurrent amplitude was observed. The pipette was frontfilled with toxin-free solution to avoid interference with seal formation. $A$, Right, In a similar experiment conducted in a photoreceptor treated with NAD alone, no sign of deterioration of the light response was observed. $B$, Shown is the normalized peak amplitude of the photoresponses for the same two cells, plotted as a function of time. Light intensity, $9 \times 10^{13}$ photons $\times \mathrm{sec}^{-1} \times \mathrm{cm}^{-2}$.

(Barnette et al., 1983). To rule out that the observed effects may be mediated by $\mathrm{CaM}$, we performed control experiments with chemically distinct CaM antagonists; neither calmidazolium (100 nM; $n=6)$ nor $\mathrm{W}-7(50 \mu \mathrm{M} ; n=2)$ applied internally produced any change in membrane current.

Most $G_{o}$ and $G_{i}$ are strongly susceptible to inhibition via ADP ribosylation by pertussis toxin (Kaslow and Burns, 1992) (for review, see Carty, 1994). The holotoxin, which is produced by the bacterium Bordetella pertussis, is composed of the A-protomer, where the catalytic activity of the toxin resides, and the B-oligomer, for which the function is to bind to the cell surface and promote internalization (Tamura et al., 1983). Effective PTX treatment of intact cells typically entails prolonged incubations, sometimes in excess of $24 \mathrm{hr}$. We determined that isolated scallop retinas can remain viable for up to $30 \mathrm{hr}$, provided they are kept at $14-16^{\circ} \mathrm{C}$. Under these conditions the addition of $1 \mu \mathrm{g} / \mathrm{ml}$ PTX to the bathing medium did not lead to a significant deterioration of the light response (data not shown). These negative results, however, could stem from poor internalization, either because of the lack of surface receptors for the B-oligomer (Tamura et al., 1983) or because of the rather low temperatures at which the cells had to be incubated (Holz et al., 1986). We therefore resorted to direct application of the toxin by intracellular dialysis via the patch electrode. Because this approach renders the B-oligomer unnecessary, we used the A-protomer instead of the holotoxin, because its smaller size $(28 \mathrm{kDa})$ expedites dialysis. Figure $6 A$, left, shows that, when the A-protomer of PTX (3 $\mu \mathrm{g} / \mathrm{ml})$ was codialyzed with 500 $\mu \mathrm{M}$ nicotinamide adenosine dinucleotide (NAD) (which serves as the donor of ADP-ribose in the ADP-ribosyltransferase reaction) (Kaslow and Burns, 1992), the photoresponse evoked by repetitive flashes $(1 / \mathrm{min})$ progressively declined over a period of $20 \mathrm{~min}$ (average photocurrent decrease, $59 \pm 11 \%$; $n=10$ ). In contrast, 
Figure 7. Intracellular dialysis of PDE inhibitors. $A$, Effect of IBMX. Left, Baseline holding current during internal perfusion with $500 \mu \mathrm{M}$ IBMX in the dark. Membrane current measured at $1 \mathrm{~min}$ intervals starting immediately after the whole-cell configuration was established did not change appreciably. Each point represents the average of nine cells; error bars indicate SD. Right, Peak light response plotted as a function of time in a photoreceptor dialyzed with $500 \mu \mathrm{M}$ IBMX, showing a progressive enhancement in amplitude. The inset illustrates individual superimposed photocurrent traces. $B, C$, Similar measurements of the lightevoked current in cells dialyzed with $200 \mu \mathrm{M}$ dipyridamole and $500 \mu \mathrm{M}$ zaprinast, respectively. The flash intensity was $1.1 \times 10^{14}$ photons $\times$ $\mathrm{sec}^{-1} \times \mathrm{cm}^{-2}$ for all measurements shown in the figure. Calibration in insets: $200 \mathrm{pA}, 200 \mathrm{msec}$.
A

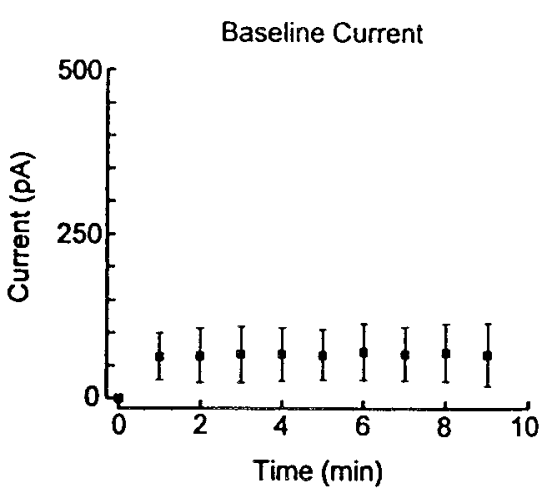

B

IBMX

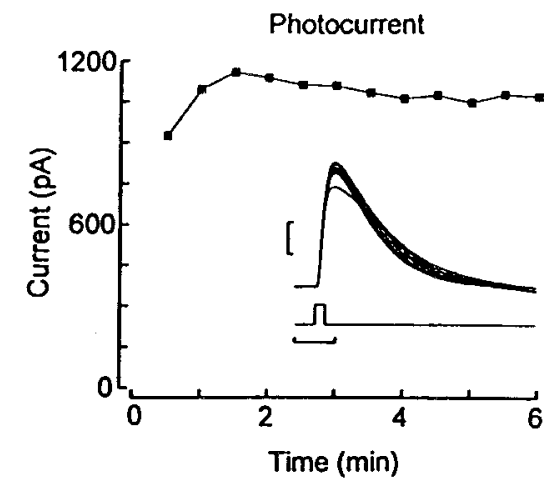

C

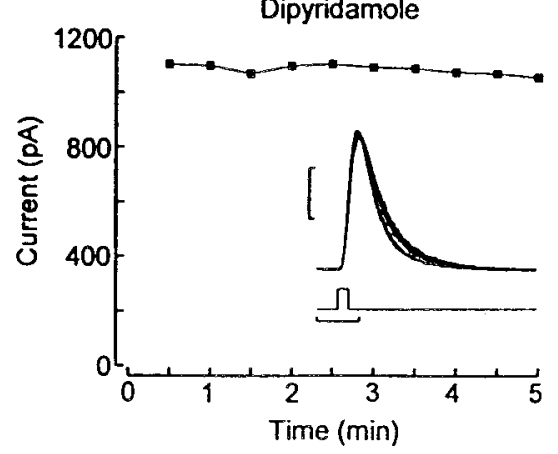

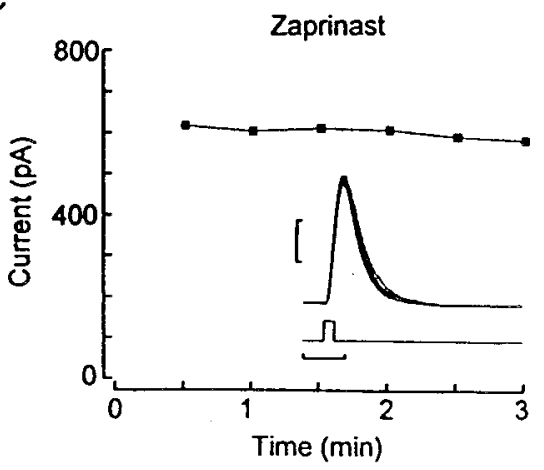

responsiveness remained unaltered in control photoreceptors treated with NAD alone (right; $n=3$ ) or with the standard internal solution $(n>20$; data not shown). In Figure $6 B$ the peak amplitude of the light response is plotted for the two cells to show the time course of the effect.

\section{Effect of PDE inhibitors}

Next we explored the mechanisms by which the G-protein is coupled to the changes in cyclic GMP necessary for opening the light-dependent conductance. Considering the well established precedent of a light-activated PDE in vertebrate phototransduction and the aforementioned kinship between rods and cones and invertebrate ciliary photoreceptors, we examined the possible involvement of a PDE modulated by light. Of course, the requirement of a photo-induced increase in cGMP would call for a high basal level of PDE activity in the dark, which would have to be reduced by light stimulation, unlike in vertebrate retinas. Under this hypothesis a pharmacological antagonist targeting PDE should be particularly effective in the dark, when the hydrolytic activity is maximal, and result in a build-up of cGMP levels and the consequent opening of light-sensitive channels. In other words, an effective PDE inhibitor should mimic photostimulation. On the other hand, the current evoked by a flash may be expected to decrease, if anything, owing to the reduced pool of PDE that may remain susceptible to inhibition by light and also owing to the fact that a fraction of ion channels already would be active.

We first tested the effect of IBMX, a broad-spectrum PDE inhibitor, applied internally via the patch pipette. As shown in Figure $7 A$, left, during intracellular perfusion with $500 \mu \mathrm{M}$ IBMX in the dark only a small change in the holding current was observed (average, $58 \pm 34 \mathrm{pA} ; n=12$ ); this was not significantly different from control cells. On the other hand, IBMX induced a gradual enhancement of the size of the photocurrent (right); the average increase was $46 \pm 17 \%(n=7)$. Although the latter effect is consistent with the presence of PDE activity in ciliary photoreceptors, both results argue against its involvement as a critical lightregulated step in the generation of the photoresponse. Attempts to narrow the identity of the PDE subtype by using more selective pharmacological inhibitors (for review, see Beavo, 1995) were unsuccessful. In particular, we tried to target cyclic nucleotide PDEs that exhibit a high substrate specificity and preferentially hydrolyze cGMP, such as types 5 and 6 (Gillespie and Beavo, 1989); however, neither dipyridamole $(100 \mu \mathrm{M} ; n=7)$ nor zaprinast $(100-500 \mu \mathrm{M}$; $n=9$ ) applied intracellularly caused any discernible change in the holding current in the dark or in the amplitude of the light responses (Fig. $7 B, C$ ). We also tested a variety of compounds that are effective on other subclasses of PDEs, including cGMP-stimulated type 2 PDE (EHNA 1-100 $\mu \mathrm{M}$ ), cGMP-inhibited type 3 PDE (trequinsin, 20-200 nM; milrinone, $5 \mu \mathrm{M}$ ), and CaM PDE type 1 (8-methoxymethyl-IBMX, 10-30 $\mu \mathrm{M}$; W-7, $50 \mu \mathrm{M}$ ); all were found to be inert.

In a recent brief communication Shimatani and Katagiri (1997) reported that bath application of IBMX and dipyridamole depressed the photoresponse in hyperpolarizing receptors of another species of scallop. We confirmed these effects in Pecten; as shown in Figure $8 A$, extracellular local application of $1 \mathrm{mM}$ IBMX reversibly decreased the amplitude of the light response (mean reduction, $54 \pm 12 \% ; n=8)$. In the dark the holding current was unaffected. A similar reduction of the photocurrent also was induced by puffer administration of $200 \mu \mathrm{M}$ dipyridamole (mean reduction, $42 \pm 6 \%$; $n=6$; Fig. $8 B$ ). This inhibitory action was not shared by other antagonists of PDE types 5 and 6 , because zaprinast $(200-400 \mu \mathrm{M})$ had no significant effect (Fig. $8 C ; n=6$ ).

The antagonistic effects of extracellular dipyridamole and IBMX on the photoresponse contrast with the ineffectiveness of these drugs applied directly to the cytosolic compartment (see above). Furthermore, they are seemingly inconsistent with the notion of a light-induced increase in cGMP. In an attempt to clarify this puzzle, we examined the consequence of dipyridamole superfusion on the current directly evoked by cGMP analogs. Figure $9 A$ shows recordings from photoreceptors voltage-clamped in the dark with electrodes containing $50 \mu \mathrm{M} 8$-Br-cGMP. A large outward current developed soon after intracellular dialysis was begun; when its amplitude reached a stable level, either $200 \mu \mathrm{M}$ (left) or $400 \mu \mathrm{M}$ dipyridamole (right) was applied from a puffer 
A

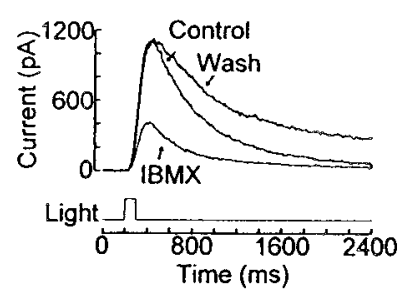

B
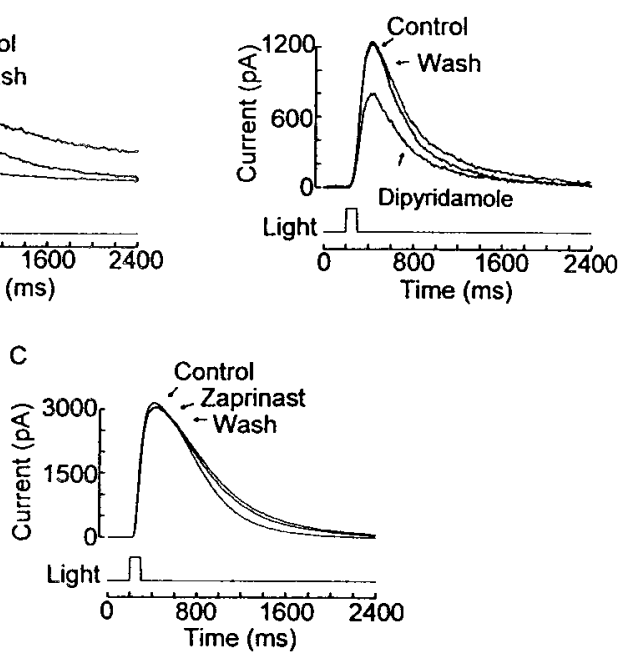

Figure 8. Extracellular effects of PDE inhibitors on the photoresponse. Repetitive flashes were applied in ASW, during puffer application of PDE inhibitors, and after the compounds were washed. $A$, IBMX locally superfused at a concentration of $1 \mathrm{~mm}$ reversibly reduced the photocurrent. Light intensity, $1.1 \times 10^{14}$ photons $\times \mathrm{sec}^{-1} \times \mathrm{cm}^{-2} . B, \mathrm{~A}$ similar effect was produced by $200 \mu \mathrm{M}$ dipyridamole $\left(2.8 \times 10^{14}\right.$ photons $\left.\times \mathrm{sec}^{-1} \times \mathrm{cm}^{-2}\right)$. $C$, Lack of effect of local application of $200 \mu \mathrm{M}$ zaprinast $\left(4.4 \times 10^{14}\right.$ photons $\times \mathrm{sec}^{-1} \times \mathrm{cm}^{-2}$ ).

pipette. A dose-dependent reversible decrease of the nucleotideevoked current was observed, which was quantitatively comparable to the reduction of the light-evoked current. In Figure 9B, control experiments performed in the absence of 8-Br-cGMP showed little effect of dipyridamole, confirming that this drug specifically acts on the cGMP-dependent $\mathrm{K}^{+}$current. These results, therefore, strongly argue that the depression of the light response by extracellular dipyridamole (and, presumably, by IBMX) stems from direct blockage of the nucleotide-dependent channels and cannot be attributable to any effect on PDE. The lack of effect of cytosolic perfusion suggests that the blocking site is only accessible extracellularly.

Disposal of cGMP also could occur by extrusion via a membrane transporter, as recently described in erythrocytes (Schultz et al., 1998). Conceivably, modulation of efflux could control intracellular [cGMP]. However, application of $100 \mu \mathrm{M}$ probenecid, a blocker of the cGMP pump, had no effect of membrane conductance in the dark nor on the light response $(n=3)$.

\section{Role of a guanylate cyclase}

A plausible alternative to regulation of hydrolysis or extrusion of cGMP as a mechanism to increase its concentration during illumination would be the modulation of a GC. The inhibitory effects of the compound LY83583 on GC have been documented extensively in biochemical assays and physiological measurements (Schmidt et al., 1985). Intracellular perfusion of ciliary photoreceptors with 10-100 $\mu \mathrm{M}$ LY83583 caused a substantial, progressive decay in the photocurrent, as shown in Figure $10 A$; the peak amplitude of the response is plotted as a function of time for a control cell (open squares) and for one voltage-clamped with an electrode containing $100 \mu \mathrm{M}$ LY83583 ( filled squares). At this concentration of the drug the responses decreased by $(52 \pm 17 \% ; n=6)$. Taking advantage of the fact that LY83583 is significantly membrane-permeable (Schmidt et al., 1985), we also examined the effect of extracellular application. Figure $10 \mathrm{~B}$ shows the light-evoked current from a cell voltage-clamped at $-30 \mathrm{mV}$; application of $200 \mu \mathrm{M} \mathrm{LY83583} \mathrm{via} \mathrm{a}$ puffer pipette reversibly decreased the size of the photocurrent (mean reduction, $53 \pm 16 \% ; n=4)$. Lower doses $(50 \mu \mathrm{M})$ were also consistently effective, although the inhibitory effect was correspondingly less pronounced ( $21 \pm 4 \% ; n=5$; data not shown). Figure $10 C$ shows intensity series recorded from a cell in ASW and during exposure to $200 \mu \mathrm{M} \mathrm{LY83583} \mathrm{(right).} \mathrm{The} \mathrm{corresponding} \mathrm{plot}$ of the peak amplitude of the photocurrents as a function of light intensity (left) shows that the curve obtained in the presence of the drug is compressed considerably.

The depression of the photocurrent by LY83583 is compatible with an inhibitory effect on GC activity; however, in view of a recent observation that in olfactory neurons this substance also can block cyclic nucleotide-gated channels (Leinders-Zufall and Zufall, 1995), it was important to rule out any direct antagonism on the light-sensitive conductance. To examine this possibility, we tested the effects of LY83583 on the current activated by direct application of cGMP analogs. Figure $10 \mathrm{D}$ shows a recording obtained in the dark from a photoreceptor whole-cell-clamped with an electrode containing $20 \mu \mathrm{M} 8$ 8-Br-cGMP. When the cGMP-dependent outward current reached a stable level, LY83583 (200 $\mu \mathrm{M})$ was applied locally (left). No reduction in current was detected, although a subsequent test in the same cell demonstrated that the light response exhibited a normal susceptibility to the drug (right), confirming the effectiveness of delivery. Similar results were obtained in 10 photoreceptors.

To ascertain the possible involvement of a nitric oxide pathway that may target a GC, we tested the effects of ODQ, a potent and selective inhibitor of nitric oxide-sensitive GC (Garthwaite et al., 1995). Repetitive photostimulation during internal dialysis with 1 $\mu \mathrm{M}$ ODQ did not reveal any decrease in response amplitude; furthermore, light sensitivity, measured in a standard intensity series, was normal $(n=5)$. Responsiveness to light also was maintained during local extracellular application of $1 \mu \mathrm{M}$ ODQ, although a marginal decrease in the peak size of the photocurrent was observed $(93 \pm 1.9 \%$ of control; $n=4)$. In addition, we determined that the light response was completely unaffected by intracellular administration of the NO-synthase inhibitor $\mathrm{N}$ methyl-L-arginine (NMLA) at a concentration of $100 \mu \mathrm{M}(n=3)$, and neither the basal conductance not the photocurrent was altered by YC-1 $(30 \mu \mathrm{M})$, an activator of NO-sensitive GC $(n=4)$. These results argue against the involvement of a $\mathrm{NO}$-sensitive $\mathrm{GC}$ in the excitatory process of ciliary photoreceptors.

\section{DISCUSSION}

In the present study we examined the intervening steps that link photopigment stimulation to ion channel gating in ciliary invertebrate photoreceptors. These cells share with vertebrate rods and cones the fact that light-dependent channels are controlled via cGMP (Gomez and Nasi, 1995), but the transduction cascade must differ at some key enzymatic step, because the final effect of photostimulation is an increase, rather than a decrease, in membrane conductance.

The effects of nonhydrolyzable guanine nucleotide analogs indicated that, in common with other visual cells, activation of a G-protein is a key early step in excitation; intracellular dialysis with low doses of GTP- $\gamma$-S caused part of the photocurrent to persist after termination of a light stimulus, concomitantly with a desensitization of the response and an acceleration of its kinetics. These effects suggest that hindering G-protein deactivation interferes with the shut-off of the phototransduction cascade and results in a state akin to adaptation by background illumination. Conversely, GDP- $\beta$-S depressed responsiveness in a manner that did not depend on photostimulation, as one would expect from the fact that GDP- $\beta$-S targets the inactive G-protein. The particular G-protein subtype that mediates phototransduction must differ from those that operate in other visual cells, because neither $G_{t}$ nor $G_{q}$ is a viable candidate in this system. Motivated by a recent report demonstrating that $G_{o}$ is present in the distal retina of a closely related species (Kojima et al., 1997), we sought physiological evidence for $\mathrm{G}_{\mathrm{o}}$ involvement in visual excitation in Pecten. In the first place, we found that mastoparan peptides known to activate $G_{i}$ and $G_{o}$ selectively, with little effect on $G_{t}$ and $G_{s}$ (Higashijima et al., 1988), consistently evoked an outward current similar to that elicited by intracellular perfusion with cGMP analogs and susceptible to the same blockers of the light/cGMP-sensitive conductance, 
Intracellular 8-Br-cGMP (50 $\mu \mathrm{M})$
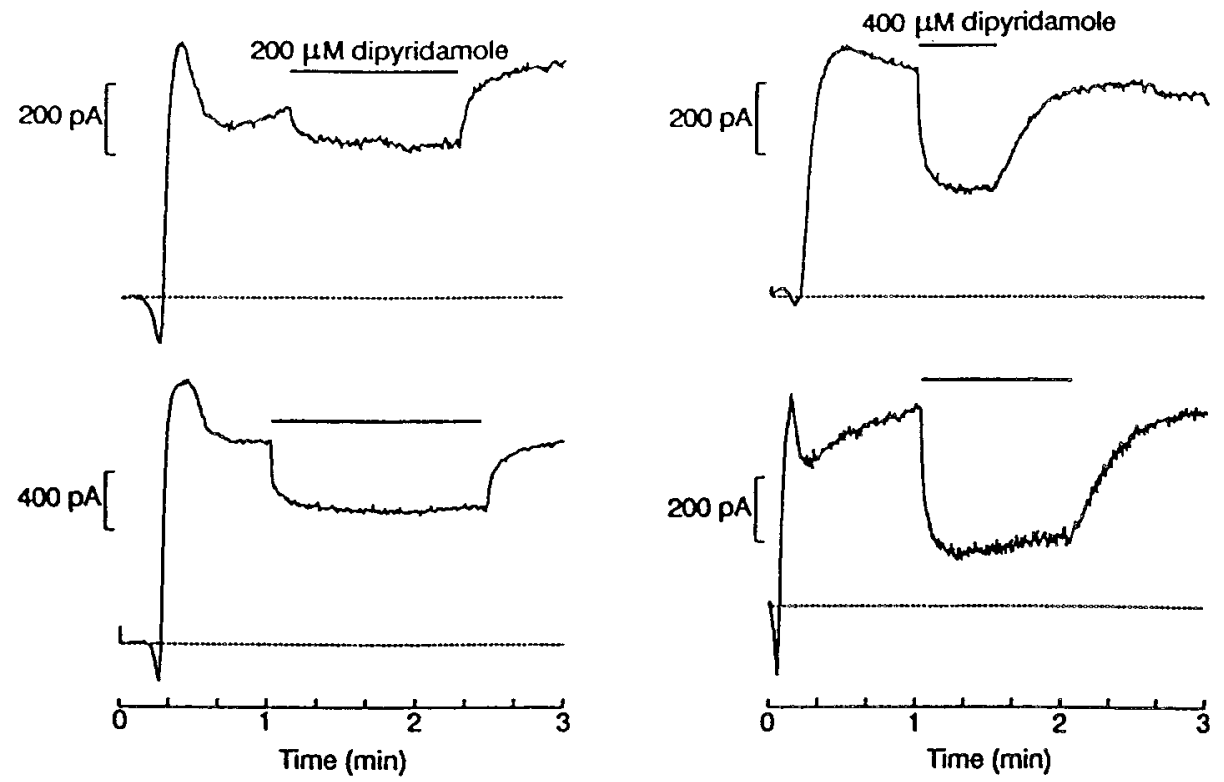

B

Control

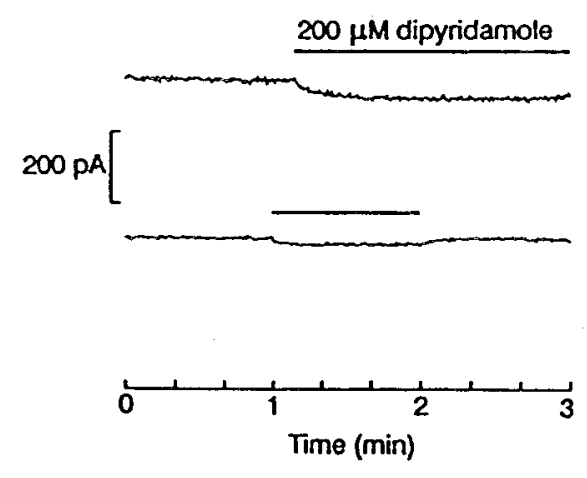

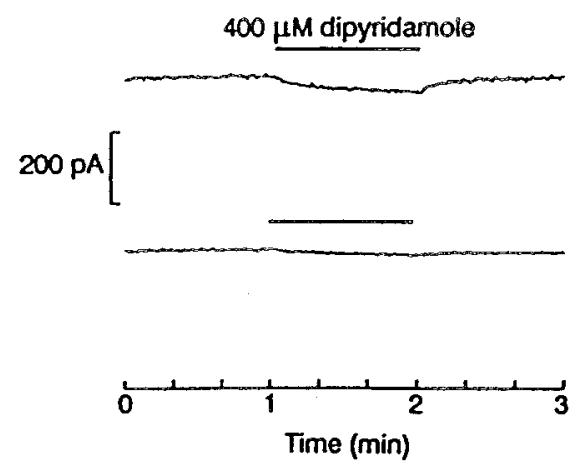

Figure 9. Photocurrent depression by dipyridamole is attributable to channel block. $A$, Shown are outward currents evoked in four cells by internal administration of $50 \mu \mathrm{M} 8$-Br-cGMP in the dark. At the time marked by the thick lines, the application of dipyridamole by puffer pipette (left, $200 \mu \mathrm{M} ;$ right, $400 \mu \mathrm{M}$ ) caused a reversible suppression of the nucleotide-induced current. $B$, Shown are dark currents in four control photoreceptors dialyzed with standard intracellular solution and locally perfused with the indicated concentrations of dipyridamole. namely L-cis-diltiazem and 4-AP (Gomez and Nasi, 1994b, 1997a). Light responsiveness also was depressed by application of the A-protomer of PTX; this result dovetails with the published amino acid sequence of the scallop retinal $G_{\text {o }}$ (Kojima et al., 1997), which shows a cysteine in the fourth position from the $\mathrm{C}$ terminus, the hallmark for susceptibility to ADP ribosylation. In conjunction with the results of Kojima et al. (1997), the present observations support the notion that light transduction in ciliary invertebrate photoreceptors is mediated by a G-protein of the $\mathrm{G}_{\mathrm{o}}$ subclass, in sharp contrast with other previously studied visual receptor cells. Interestingly, in the "on" bipolar cells from vertebrate retinae the response triggered by stimulation of metabotropic glutamate receptors (which also is mediated by cGMP) (Nawy and Jahr, 1990, 1991; Shiells and Falk, 1990) appears to involve a $\mathrm{G}_{\mathrm{o}}$ (Vardi et al., 1993).

The enzymatic target of the rhodopsin-coupled G-protein also seems to differ from that of other photoreceptors that use cGMP as an internal messenger, because modulation of a phosphodiesterase is an unlikely light-regulated mechanism for controlling cGMP levels in the present system. Such a scheme would require a high constitutive level of GC activity; therefore, one would anticipate that inhibition of PDE in the dark should lead to rapid cGMP accumulation and the consequent activation of the light-sensitive conductance. Contrary to this prediction, intracellular administration of IBMX caused only marginal changes in the baseline holding current, although the current elicited by light flashes was enhanced. This suggests that, although PDE activity may be present in ciliary photoreceptors, it seems not to be regulated by light. It is interesting to note that, in a recent study of "on" bipolar cells, it also was found that IBMX did not affect adversely the cGMP-mediated metabotropic response to glutamate, indicating that a PDE may not be required for transduction in that system either (Nawy, 1999). Surprisingly, in the presence of IBMX the time course of the light response was not prolonged significantly. One would have to conclude that cGMP hydrolysis is not the main rate-limiting step in the fall of the photocurrent after a flash. The simplest tentative explanation could be that diffusion of cGMP out of the minute ciliary appendages $(\sim 1 \mu \mathrm{M})$ into the much larger cytosolic volume of the cell body $(>2000 \times)$ may account for much of the fall in cGMP concentration in the region near the light-dependent channels. Attempts to clarify the identity of the PDE of Pecten photoreceptors by pharmacological means were unsuccessful. In particular, intracellular administration of selective inhibitors of some well characterized cGMP-specific PDEs (types 5 and 6) failed to alter membrane current, both in the dark and after illumination. One must recognize, however, that recently discovered PDEs (Soderling et al., 1998, 1999) bring the total number of subclasses of cyclic nucleotide phosphodiesterases to at least 10, and for several of them no specific antagonists have yet been found.

The depression of the light response by extracellular dipyrida- 
A

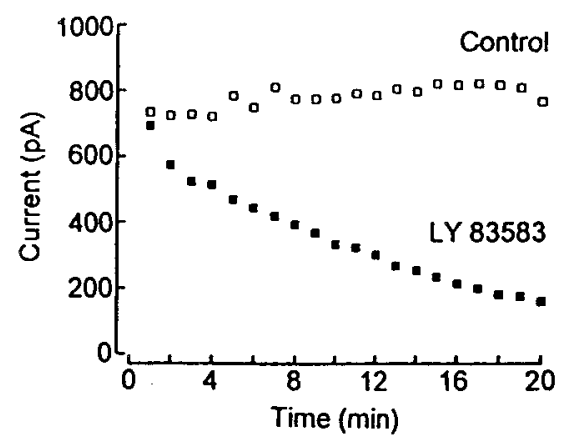

C

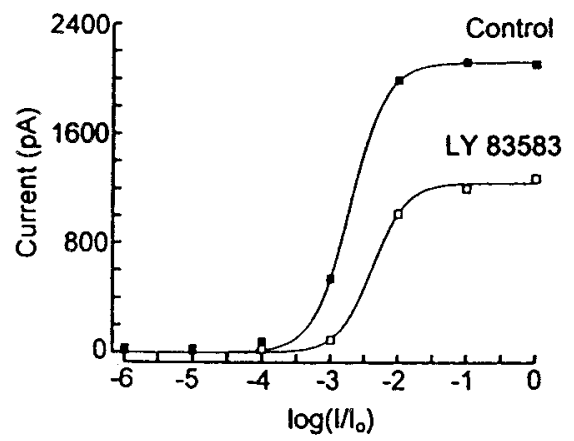

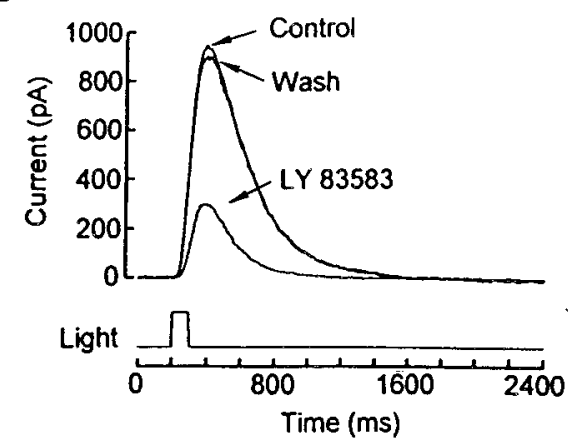

D

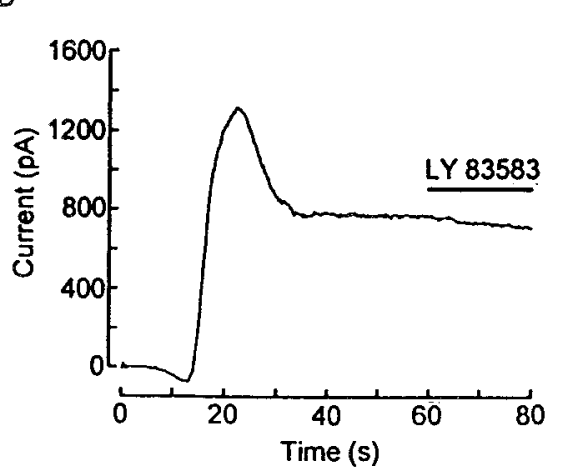

8-Br-CGMP

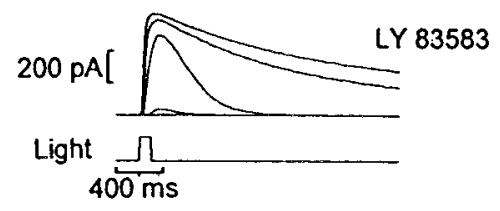

Figure 10. Depression of the photocurrent by inhibition of guanylate cyclase. $A$, Peak amplitude of the light response elicited by repetitive flashes, plotted as a function of time. The pipette contained either the normal intracellular solution (open squares) or 100 $\mu \mathrm{M}$ LY83583 (filled squares). The light intensity was $2.3 \times 10^{14}$ photons $\times \mathrm{sec}^{-1} \times \mathrm{cm}^{-2}$. $B$, Reversible inhibition of the photocurrent induced by extracellular application of 200 $\mu \mathrm{M}$ LY83583; the same light stimuli are used as in $A$. $C$, Photocurrent amplitude as a function of light intensity in a cell dialyzed with standard internal solution (unattenuated light intensity, $3.4 \times 10^{15}$ photons $\times \sec ^{-1} \times$ $\left.\mathrm{cm}^{-2}\right)$. The intensity series was recorded in ASW (filled squares) and during local superfusion with $200 \mu \mathrm{M}$ LY83583 (open squares). The corresponding families of raw traces are shown on the right. D, Left, Outward current evoked by internal perfusion with $20 \mu \mathrm{M}$ 8-Br-cGMP in the dark. Once the cGMPdependent current reached a steady state, LY83583 was applied with a puffer pipette but produced no measurable effect. Subsequent application of the drug in the same cell (right) reduced the photocurrent in a reversible manner. Light intensity, $18 \times 10^{14}$ photons $\times$ $\mathrm{sec}^{-1} \times \mathrm{cm}^{-2}$. mole and IBMX was unexpected, given the robust and well documented observation that cGMP analogs activate the lightdependent $\mathrm{K}^{+}$conductance. Closer scrutiny of this phenomenon led to the conclusion that it was attributable to a direct antagonism on the light-sensitive conductance, unrelated to any effect on PDE. Precedents for channel block by these compounds have appeared previously in the literature; in Limulus ventral photoreceptors IBMX blocks voltage-gated $\mathrm{K}^{+}$channels (Corson et al., 1979), whereas dipyrydamole has been claimed to block $\mathrm{Cl}^{-}$channels in cultured astrocytes (Sanchez-Olea et al., 1993). Our observations thus provide a clarification for a recent brief communication that, on the basis of the reduction of the photoresponse by extracellular dipyrydamole and IBMX in hyperpolarizing photoreceptors of a related species of scallop, suggested that a decrease in cGMP may underlie the visual excitation process (Shimatani and Katagiri, 1997).

The results of the present study lend support to an alternative scheme, according to which light-triggered activation of the G-protein is coupled to stimulation of a GC to produce the increase in cGMP required to open light-dependent channels. In agreement with this notion, the GC inhibitor LY83583 consistently and reversibly depressed the photoresponse in a dose-dependent manner. By contrast, no inhibition by this compound was detected when the light-sensitive channels were opened directly by $8-\mathrm{Br}$ cGMP, demonstrating that the site of action of LY83583 is upstream in the cascade. GCs are broadly grouped in two categories: soluble, which are regulated by NO (for review, see Hobbs, 1997), and particulate or membrane. LY83583 has been known to target both soluble (Kontos and Wei, 1993) and membrane GCs (Clemo et al., 1992). However, in Pecten ciliary photoreceptors the manipulations designed to interfere with $\mathrm{NO}$ synthase produced no effect, arguing against a NO pathway that may impinge onto cGMP signaling. Moreover, ODQ, a selective antagonist of the NOsensitive GC, failed to alter the light response, and application of YC-1, a specific activator of NO-sensitive GC, produced no effect on the basal membrane conductance. Taken together, these results seem to rule out the involvement of a soluble GC in phototransduction; by exclusion, a membrane GC may be implicated. Several membrane GCs have an extracellular receptor domain that confers them responsiveness to ligands such as atrial natriuretic peptide or pheromones (for review, see Wedel and Garbers, 1997). Other members of this class interact with regulatory proteins via the membrane-proximal stretch of the cytosolic domain and therefore can play a role in intracellular signaling. In particular, the GCs found in the outer segment of vertebrate rods bind GC-activating proteins (GCAPs) (for review, see Polans et al., 1996), which can 
stimulate catalytic activity in a Ca-dependent manner, a mechanism crucially implicated in light adaptation and dark current recovery. It is clear, however, that in the case of Pecten different functional properties would be expected, because previous evidence argues against any critical role of calcium ions in phototransduction (Gomez and Nasi, 1995) or its modulation (Gomez and Nasi, 1997b). The required linkage of rhodopsin stimulation to GC activity, whether direct or indirect, remains to be elucidated, because little is known about mechanisms that may couple G-proteins to GCs, and clues are only beginning to emerge in other systems. For example, in Dictyostelium the chemotactic response triggered by extracellular cAMP has been shown to be mediated by a G-protein that stimulates a membrane GC, causing an elevation of cGMP levels (Kuwayama and Van Haastert, 1998). A GC/atrial natriuretic factor receptor in the plasma membrane of murine Leydig tumor cells also appears to be regulated by $\mathrm{G}_{\mathrm{s}} / \mathrm{G}_{\mathrm{i}}$ (Khurana and Pandey, 1995). Although there are no precedents for light regulation of a GC mediating the generation of the receptor potential in retinal receptors, a similar mechanism recently has been proposed to operate in the extra-ocular light-sensitive neuron of a mollusk (Nishi and Gotow, 1998); moreover, such a scheme parallels the well documented transduction process of other sensory cells of ciliary origin, such as the neurons of the olfactory epithelia where odorants activate an adenylate cyclase to bring about an increase in cAMP (Pace et al., 1985). The notion that a $G_{0}$ mediates light transduction in Pecten ciliary photoreceptors by stimulating a GC would place these cells in a novel, separate subgroup among visual receptors, which may share significant similarities with chemoreceptor cells.

\section{REFERENCES}

Andrade R (1994) Infusion of guanine nucleotides through recording electrodes for studies on G-protein regulation of ion currents and channels. Methods Enzymol 238:348-356.

Baer KM, Saibil HR (1988) Light- and GTP-activated hydrolysis of phosphatidylinositol bisphosphate in squid photoreceptor membranes. J Biol Chem 263:17-20.

Barnette MS, Daly R, Weiss B (1983) Inhibition of calmodulin activity by insect venom peptides. Biochem Pharmacol 32:2929-2933.

Baylor DA, Hodgkin AL (1974) Changes in time scale and sensitivity in turtle photoreceptors. J Physiol (Lond) 242:729-758.

Beavo J (1995) Cyclic nucleotide phosphodiesterases: functional implications of multiple isoforms. Physiol Rev 75:725-748.

Breitwieser GE, Szabo G (1988) Mechanism of muscarinic receptorinduced $\mathrm{K}^{+}$channel activation as revealed by hydrolysis-resistant GTP analogues. J Gen Physiol 91:469-493.

Brown JE, Blinks JR (1974) Changes in intracellular free calcium concentration during illumination of invertebrate photoreceptors. J Gen Physiol 64:643-665.

Brown JE, Rubin LJ (1984) A direct demonstration that inositol trisphosphate induces an increase in intracellular calcium in Limulus photoreceptors. Biochem Biophys Res Commun 125:1137-1142.

Brown JE, Watkins DC, Malbon CC (1987) Light-induced changes in the content of inositol phosphate in squid (Loligo pealei) retina. Biochem $\mathrm{J}$ 247:293-297.

Carty DJ (1994) Pertussis toxin-catalyzed ADP-ribosylation of G-proteins. Methods Enzymol 237:63-71.

Clemo HF, Feher JJ, Baumbarten CM (1992) Modulation of rabbit ventricular cell volume and $\mathrm{Na}^{+} / \mathrm{K}^{+} / 2 \mathrm{Cl}^{-}$cotransport by cGMP and atrial natriuretic factor. J Gen Physiol 100:89-114.

Corson DW, Fein A, Schmidt J (1979) Two effects of phosphodiesterase inhibitors on Limulus ventral photoreceptors. Brain Res 176:365-368.

Devary O, Heichal O, Blumenfeld A, Cassel D, Suss E, Barash S, Rubinstein CT, Minke B, Selinger Z (1987) Coupling of photoexcited rhodopsin to inositol phospholipid hydrolysis in fly photoreceptors. Proc Nat Acad Sci USA 84:6939-6943.

Eckstein R, Cassel D, Levkovitz H, Sellinger Z (1979) Guanosine 5'-O(2-thiodiphosphate): an inhibitor of adenylate cyclase stimulation by guanine nucleotides and fluoride ions. J Biol Chem 254:9829-9834.

Fuortes MGF, Hodgkin AL (1964) Changes in time scale and sensitivity in the ommatidia of Limulus. J Physiol (Lond) 172:239-263.

Garthwaite J, Southam E, Boulton CL, Nielsen EB, Schmidt K, Mayer B (1995) Potent and selective inhibition of nitric oxide-sensitive guanylyl cyclase by $1 H$-[1,2,4] oxadiazolo[4,3-a]quinoxalin-1-one. Mol Pharmacol 48:184-188.

Gillespie PG, Beavo JA (1989) Inhibition and stimulation of photoreceptor phosphodiesterases by dipyridamole and M\&B 22,948. Mol Pharmacol 36:773-781.

Gomez M, Nasi E (1994a) The light-sensitive conductance of hyperpolar- izing invertebrate photoreceptors: a patch-clamp study. J Gen Physiol 103:939-956.

Gomez M, Nasi E (1994b) Blockage of the light-sensitive conductance in hyperpolarizing photoreceptors of the scallop. Effects of tetraethylammonium and 4-aminopyridine. J Gen Physiol 104:487-505.

Gomez M, Nasi E (1995) Activation of light-dependent potassium channels in ciliary invertebrate photoreceptors involves cGMP but not the $\mathrm{IP}_{3} / \mathrm{Ca}$ cascade. Neuron 15:607-618.

Gomez M, Nasi E (1996) Ion permeation through light-activated channels in rhabdomeric photoreceptors: role of divalent cations. J Gen Physiol 107:715-730.

Gomez M, Nasi E (1997a) Antagonists of the cGMP-gated conductance of vertebrate rods block the photocurrent in scallop ciliary photoreceptors. J Physiol (Lond) 500:367-378.

Gomez M, Nasi E (1997b) Light adaptation in Pecten hyperpolarizing photoreceptors: insensitivity to $\mathrm{Ca}$ manipulations. J Gen Physiol 109:371-384.

Gorman ALF, McReynolds JS (1978) Ionic effects on the membrane potential of the hyperpolarizing photoreceptors in scallop retina. J Physiol (Lond) 275:345-355.

Higashijima T, Uzu S, Nakajima T, Ross EM (1988) Mastoparan, a peptide toxin from wasp venom, mimics receptors by activating GTP-binding regulatory proteins (G-proteins). J Biol Chem 263:6491-6494.

Hobbs AJ (1997) Soluble guanylate cyclase: the forgotten sibling. Trends Pharmacol Sci 18:484-491.

Holz GG, Rane SG, Dunlap K (1986) GTP-binding proteins mediate transmitter inhibition of voltage-dependent calcium channels. Nature 319:670-672.

Kaslow HR, Burns DL (1992) Pertussis toxin and target eukaryotic cells: binding, entry, and activation. FASEB J 6:2684-2690.

Khurana ML, Pandey KN (1995) Catalytic activation of guanylate cyclase/ atrial natriuretic factor receptor by combined effects of ANF and GTP$\gamma-\mathrm{S}$ in plasma membranes of Leydig tumor cells: involvement of G-proteins. Arch Biochem Biophys 316:392-398.

Kojima D, Terakita A, Ishikawa T, Tsukahara Y, Maeda A, Shichida Y (1997) A novel $G_{\mathrm{o}}$-mediated phototransduction cascade in scallop visual cells. J Biol Chem 272:22979-22982.

Kontos HA, Wei EP (1993) Hydroxyl radical-dependent inactivation of guanylate cyclase in cerebral arterioles by methylene blue and by LY83583. Stroke 24:427-434.

Kuwayama H, Van Haastert PJM (1998) Chemotactic and osmotic signals share a cGMP transduction pathway in Dictyostelium discoideum. FEBS Lett 424:248-252.

Lee YJ, Shah S, Suzuki E, Zars T, O'Day PM, Hyde DR (1994) The Drosophila $d g q$ gene encodes a $\mathrm{G}_{\alpha}$-protein that mediates phototransduction. Neuron 13:1143-1157.

Leinders-Zufall T, Zufall F (1995) Block of cyclic nucleotide-gated channels in salamander olfactory receptor neurons by the guanylyl cyclase inhibitor LY83583. J Neurophysiol 74:2759-2762.

McReynolds JS (1976) Hyperpolarizing photoreceptors in invertebrates. In: Neural principles in vision (Zettler F, Weiler R, eds), pp 394-409. Berlin: Springer.

Miller WH (1958) Derivatives of cilia in the distal sense cells of the retina of Pecten. J Biophys Biochem Cytol 4:227-228.

Nasi E (1991) Electrophysiological properties of isolated photoreceptors from the eye of Lima scabra. J Gen Physiol 97:17-34.

Nawy S (1999) The metabotropic receptor mGluR6 may signal through $\mathrm{G}_{\mathrm{o}}$, but not phosphodiesterase, in retinal bipolar cells. J Neurosci 19:2938-2944.

Nawy S, Jahr CE (1990) Suppression by glutamate of cGMP-activated conductance in retinal bipolar cells. Nature 346:269-271.

Nawy S, Jahr CE (1991) CGMP-gated conductance in retinal bipolar cells is suppressed by the photoreceptor transmitter. Neuron 7:677-683.

Nishi T, Gotow T (1998) Light-increased cGMP and $\mathrm{K}^{+}$conductance in the hyperpolarizing receptor potential of Onchidium extra-ocular photoreceptors. Brain Res 809:325-336.

Pace U, Hanski E, Salomon Y, Lancet D (1985) Odorant-sensitive adenylate cyclase may mediate olfactory reception. Nature 316:255-258.

Polans A, Baehr W, Palczewski K (1996) Turned on by $\mathrm{Ca}^{2+}$ : the physiology and pathology of $\mathrm{Ca}^{2+}$-binding proteins in the retina. Trends Neurosci 19:547-554

Sanchez-Olea R, Peña C, Moran J, Pasantes-Morales H (1993) Inhibition of volume regulation and efflux of osmoregulatory amino acids by blockers of $\mathrm{Cl}^{-}$transport in cultured astrocytes. Neurosci Lett 156:141-144.

Schmidt MJ, Sawyer BD, Truex LL, Marshall WS, Fleisch JH (1985) LY83583: an agent that lowers intracellular levels of cyclic guanosine 3',5'-monophosphate. J Pharmacol Exp Ther 232:764-769.

Schultz C, Vaskinn S, Kildalsen H, Sager G (1998) Cyclic AMP stimulates the cyclic GMP egression pump in human erythrocytes: effects of probenecid, verapamil, progesterone, theophylline, IBMX, forskolin, and cyclic AMP on cyclic GMP uptake and association in inside-out vesicles. Biochemistry 37:1161-1166.

Scott K, Becker A, Sun Y, Hardy R, Zuker C (1995) $\mathrm{G}_{\mathrm{q}} \alpha$-protein function in vivo: genetic dissection of its role in photoreceptor cell physiology. Neuron 15:919-927.

Shiells RA, Falk G (1990) Glutamate receptors of rod bipolar cells are 
linked to a cyclic GMP cascade via a G-protein. Proc R Soc Lond [Biol] 242:91-94.

Shimatani Y, Katagiri Y (1997) Phototransduction in scallop hyperpolarizing photoreceptors involves the hydrolysis of cyclic GMP. Invest Ophthalmol Vis Sci 38:S23.

Soderling SH, Bayuga SJ, Beavo JA (1998) Identification and characterization of a novel family of cyclic nucleotide phosphodiesterases. J Biol Chem 273:15553-15558.

Soderling SH, Bayuga SJ, Beavo JA (1999) Isolation and characterization of a dual-substrate phosphodiesterase gene family: PDE10A. Proc Nat Acad Sci USA 96:7071-7076.

Suh B-C, Song S-K, Kim Y-K, Kim K-T (1996) Induction of cytosolic $\mathrm{Ca}^{2+}$ elevation mediated by MAS-7 occurs through membrane pore formation. J Biol Chem 271:32753-32759.

Suzuki T, Narita K, Yoshihara K, Nagai K, Kito Y (1995) Phosphatidyl inositol-phospholipase $\mathrm{C}$ in squid photoreceptor membrane is activated by stable metarhodopsin via GTP-binding protein, $\mathrm{G}_{\mathrm{q}}$. Vision Res 35:1011-1017.

Szuts EZ, Woods SF, Reid MS, Fein A (1986) Light stimulates the rapid formation of inositol trisphosphate in squid retinas. Biochem $\mathrm{J}$ 240:929-932.

Tamura M, Nogimori K, Yajima M, Ase K, Ui M (1983) A role of the B-oligomer moiety of islet-activating protein, pertussis toxin, in development of the biological effects on intact cells. J Biol Chem 258:6756-6761.

Tanimura A, Matsumoto Y, Tojyo Y (1991) Mastoparan increases membrane permeability in rat parotid cells independently of action on G-proteins. Biochem Biophys Res Commun 177:802-808.

Vardi N, Matesic DF, Manning DR, Liebman PA, Sterling P (1993) Identification of a G-protein in depolarizing rod bipolar cells. Vis Neurosci 10:473-478.

Wedel BJ, Garbers DL (1997) New insights on the functions of the guanylyl cyclase receptors. FEBS Lett 410:29-33.

Xiong W-H, Solessio EC, Yau K-W (1998) An unusual cGMP pathway underlying depolarizing light responses of the vertebrate parietal-eye photoreceptor. Nat Neurosci 1:359-365.

Yau K-W, Baylor DA (1989) Cyclic GMP-activated conductance of retinal photoreceptor cells. Annu Rev Neurosci 12:289-327. 